Case Reports in
Gastroenterology
Case Rep Gastroenterol 2020;14:624-631

DOI: $10.1159 / 000511037$

Published online: November 24, 2020

(C) 2020 The Author(s)

Published by S. Karger AG, Basel www.karger.com/crg

This article is licensed under the Creative Commons Attribution-NonCommercial 4.0 International License (CC BY-NC) (http://www.karger.com/Services/OpenAccessLicense). Usage and distribution for commercial purposes requires written permission.

\title{
Anaplastic Carcinoma of the Pancreas: Clinical and Morphological Characteristics
}

\author{
Valery I. Podzolkov ${ }^{a} \quad$ Anna E. Pokrovskaya ${ }^{a}$ Tatyana S. Vargina ${ }^{a}$ \\ Andrey B. Ponomarev ${ }^{b}$ Yevgenia A. Kogan ${ }^{b} \quad$ Julia V. Lerner ${ }^{b}$ \\ aDepartment of Faculty Therapy No. 2, I.M. Sechenov First Moscow State Medical

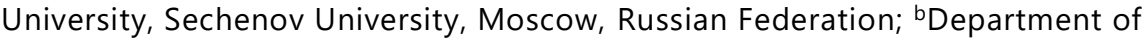 \\ Pathological Anatomy, I.M. Sechenov First Moscow State Medical University, Sechenov \\ University, Moscow, Russian Federation
}

\section{Keywords}

Anaplastic pancreatic cancer · Undifferentiated pancreatic cancer · Oncomarker $\cdot \alpha$ Fetoprotein · Carcinoembryonic antigen

\section{Abstract}

Anaplastic pancreatic carcinoma is a very rare histological subtype of pancreatic cancer, which is characterized by a more aggressive course than for conventional ductal adenocarcinoma. In this article, we consider the features of the clinical course, the difficulties of diagnosis in connection with the absence of pathognomonic signs of pancreatic cancer, and the morphological picture of this disease in a patient 60 years of age. This clinical case clearly demonstrates the complexities of the pancreatic carcinoma diagnosis, fast disease progression, and extremely unfavorable prognosis. It is important for clinicians to remember that this pathology often has a subclinical course, and the oncomarker levels are not always true. 


\section{Case Reports in Gastroenterology}

Case Rep Gastroenterol 2020;14:624-631

\begin{tabular}{l|c|c|}
\hline DOI: 10.1159/000511037 & $\odot 2020$ The Author(s). Published by S. Karger AG, Basel
\end{tabular} www.karger.com/crg

Podzolkov et al.: Anaplastic Carcinoma of the Pancreas: Clinical and Morphological Characteristics

\section{Introduction}

Pancreatic carcinoma (PC) is a malignant tumor originating from the pancreatic epithelium [1]. PC amounted to 3.3\% of oncological diseases in Russia in 2015. The mean age of male patients is 64.6 years and that of female patients 70.3 years. The increase in the incidence of this pathology among men over the previous 10 years is $9.39 \%$, while among women it is $14.95 \%$. In the statistics of mortality from cancer in Russia in 2015, PC mortality was 5.9\%, which puts it on the 5th place after lung, stomach, colon, and breast cancer. The mean age at death in men is 64.8 years and in women it is 71.3 years [1].

In most cases, $\mathrm{PC}$ is sporadic. The main risk factors are alcohol abuse, chronic pancreatitis, diabetes mellitus, and obesity [2,3]. The most common histopathological form is ductal adenocarcinoma, which is diagnosed in $90-95 \%$ of cases [1-3]. Other morphological variants according to the international histological classification are very uncommon. These forms include the following: adenosquamous, colloidal, hepatoid, medullary, signet ring cell, and anaplastic (undifferentiated) carcinomas. Anaplastic carcinoma is of great interest in clinical practice. According to the WHO classification of pancreatic tumors, this variant of malignant neoplasm is classified as undifferentiated forms of cancer, in which on histological examination significant tumor component has no specific signs of differentiation. However, some authors consider anaplastic cancer as a variant of pancreatic ductal carcinoma [4].

Anaplastic pancreatic cancer (APC) is an extremely rare pathology. There are no clear statistics on its incidence, but the extreme rarity of this pathology is evidenced by the fact that in the N.N. Blokhin Cancer Research Center, anaplastic carcinoma was diagnosed only in 3 cases of 1,500 interventions on pancreas [5]. According to the Pancreatic Cancer Registry in Japan from 2001 to 2004, among 27,335 registered patients, this form of cancer was detected in $0.1 \%$ of all patients with exocrine pancreatic neoplasms. APC is more common in men (63\%), and in more than $50 \%$ of cases it affects the head of the pancreas (53\%) [4].

Clinical signs of APC at the time of onset are similar to those of ductal adenocarcinoma: abdominal pain, backache, dyspepsia, jaundice, etc., although there are fundamental differences in radiological diagnostic criteria and tumor marker levels due to the different morphology [5]. Laboratory features of APC are anemia (detected in $20 \%$ of patients) and leukocytosis, which are probably caused by rapid tumor growth, intratumor hemorrhages, and necrosis [4].

APC is difficult to diagnose. So, if in ductal adenocarcinoma the oncomarker CA 19-9 level is elevated in $75-82 \%$ of cases, which allows to use it for screening according to many recommendations, then in APC an elevated level of this oncomarker occurs only in $50 \%$ of cases [4] or does not occur at all, which is due to the low differentiation of tumor cells [6].

APC has a very unfavorable prognosis. The only possible way to prolong life is radical surgery, if possible. According to Strobel et al. [6], perioperative mortality is about $39 \%$, and the median survival in patients with APC is 5.7 months, much less than in the control group of patients with ductal adenocarcinoma (15.7 months). According to the Japanese Society of Pancreatology, the median survival in patients with APC is 3.3 months, and 1- and 2-year total survival rates are 14.4 and $0 \%$, respectively [4].

Studies of APC are limited and include mainly case descriptions or tests of very small groups of patients. In this regard, the presented observation is extremely relevant. The case of an APC patient is reviewed below.

\section{Karger'=}




\section{Case Reports in Gastroenterology}

\begin{tabular}{l|l}
\hline Case Rep Gastroenterol 2020;14:624-631 \\
\hline DOI: 10.1159/000511037 & $\begin{array}{l}\text { ○ 2020 The Author(s). Published by S. Karger AG, Basel } \\
\text { www.karger.com/crg }\end{array}$ \\
\hline
\end{tabular}

Podzolkov et al:: Anaplastic Carcinoma of the Pancreas: Clinical and Morphological Characteristics

\section{Case Report}

Patient K., 60 years old, was hospitalized in the University Clinical Hospital No. 4 on September 27, 2017, in an urgent order with the referral diagnosis ascites of unknown etiology. On admission, he complained of general weakness, expressed shortness of breath, dry cough, discomfort in the epigastrium, distended abdomen, swelling of the lower legs and feet, and weakness in the legs.

\section{Anamnesis Vitae}

The patient was a chronic smoker of 1.5 packs per day. Diet: malnutrition.

\section{Anamnesis Morbi}

The examination revealed that the patient had been abusing alcohol over a long period. In June 2017, he received inpatient treatment for toxic liver cirrhosis. Investigations were performed that allowed to verify this diagnosis (esophagogastroduodenoscopy, ultrasound). In addition, oncomarkers were obtained: $\alpha$-fetoprotein (AFP) level was increased up to 10.61 $\mathrm{ng} / \mathrm{mg}$ (reference value: up to $8.1 \mathrm{ng} / \mathrm{mg}$ ), carcinoembryonic antigen and CA 19-9 levels were within normal values. After discharge, the patient did not follow recommendations and continued to abuse alcohol. From the first days of September, the patient noted deterioration: the abdomen increased in volume again, pronounced weakness developed because of which the patient could not move normally, and swelling of the lower extremities appeared.

\section{Present State}

The general state was severe. The patient was conscious on contact. The body temperature was $36.8^{\circ} \mathrm{C}$. On examination, pallor and subicteritiousness of the skin, moderate swelling of the lower legs and feet, as well as shortness of breath at rest, up to 23 breaths per minute, were noticed. At auscultation of the lungs, breathing was harsh, reduced in the lower segments, without rales. Borders of heart dullness were extended to the left by $+2.5 \mathrm{~cm}$. Heart tones were muffled, with regular rhythm, without murmur. The heart rate was $96 \mathrm{bpm}$, and blood pressure was $115 / 70 \mathrm{~mm} \mathrm{Hg}$. The tongue was wet with a light cover. When palpating, the abdomen was soft, painless, and enlarged due to ascites and subcutaneous fat. On percussion, the liver was painless and protruded below the costal margin by $+2 \mathrm{~cm}$. The lower edge of the spleen was palpable. The patient consulted a surgeon at the emergency department. He was diagnosed with tense ascites against the background of liver cirrhosis.

Clinical blood count showed signs of normochromic, normocytic anemia (red blood cells $3.10 \times 10^{12} / \mathrm{L}$, hemoglobin $88 \mathrm{~g} / \mathrm{L}$, hematocrit $26.9 \%$, mean corpuscular volume $86.8 \mathrm{fL}$, mean corpuscular hemoglobin $28.4 \mathrm{pg}$, platelets $505 \times 10^{9} / \mathrm{L}$, white blood cells $18.7 \times 10^{9} / \mathrm{L}$, erythrocyte sedimentation rate $80 \mathrm{~mm} / \mathrm{h}$ ). Markers of anemia are as follows: B12 $336 \mathrm{pmol} / \mathrm{L}$, folic acid $21.4 \mathrm{nmol} / \mathrm{L}$, and serum iron $14.2 \mu \mathrm{mol} / \mathrm{L}$; all parameters were within the normal range. Serologic markers of viral hepatitis (HbsAg, HCV antibodies), Rapid Plasma Reagin test, and HIV were negative. Urinalysis revealed minor glycosuria and moderate proteinuria $[0.040$ $\mathrm{g} / \mathrm{L})$. Fecal occult blood test was negative.

Blood biochemistry (twice) showed normal levels of total protein, total bilirubin, ALT, AST, gamma-glutamyl transpeptidase, creatine phosphokinase, potassium, and sodium. Alkaline phosphatase level was initially slightly increased to $126.6 \mathrm{U} / \mathrm{L}$ (reference range: 30-120), with following reduction to normal values. Amylase level in the first blood test was moderately reduced to $21.4 \mathrm{IU} / \mathrm{L}$ (normal value: $28-100$ ), but when repeated it was normal.

\section{Karger'=}




\section{Case Reports in Gastroenterology}

Case Rep Gastroenterol 2020;14:624-631

DOI: 10.1159/000511037

(c) 2020 The Author(s). Published by S. Karger AG, Basel www.karger.com/crg

Podzolkov et al:: Anaplastic Carcinoma of the Pancreas: Clinical and Morphological Characteristics

Moderate hyperglycemia up to $7.4 \mathrm{mmol} / \mathrm{L}$ was observed. Urea and creatinine levels were consistently high, with maximum values of $38.1 \mathrm{mmol} / \mathrm{L}$ and $1.92 \mathrm{mg} / \mathrm{dL}$, respectively. Minimum GFR (CKD-EPI) was $37 \mathrm{~mL} / \mathrm{min} / 1.73 \mathrm{~m}^{2}$ (corresponds to 3B stage of chronic kidney disease). Signs of coagulopathy were found: thrombin time, prothrombin time, and INR were increased. Prothrombin index was reduced; the minimum value was $55.7 \%$ (normal value: $85-$ 105). Hyperfibrinogenemia with a maximum value of $8.9 \mathrm{~g} / \mathrm{L}$ was noted. AFP was significantly increased up to $106 \mathrm{IU} / \mathrm{mL}$ (normal value: up to $6.7 \mathrm{IU} / \mathrm{mL}$ ). Stool analysis showed signs of exocrine pancreatic insufficiency (creatorrhea, steatorrhea, and amylorrhea).

Chest X-ray showed signs of pulmonary emphysema, pneumosclerosis, and enlargement of the heart shadow to the left. ECG showed normal sinus rhythm. Heart rate was $109 \mathrm{bpm}$. Abdominal ultrasound showed signs of right-sided hydrothorax, ascites, and dilation of the vena portae to $14 \mathrm{~mm}$ (normal value: $12 \mathrm{~mm}$ ). Diffuse changes in the liver and pancreas were found. Abdominal and retroperitoneal lymph nodes were not enlarged. Upper gastrointestinal tract endoscopy showed hiatal hernia, reflux-esophagitis, $0-1$ grade esophageal varices, and grade 1 gastric varices. Signs of superficial gastritis, significant duodenitis, and bile reflux were found. Colonoscopy showed chronic catarrhal colitis, colon lipomas, and chronic mixed hemorrhoids. The investigation was complicated due to the significant adhesions in the abdominal cavity and small pelvis.

Preliminary diagnosis was toxic liver cirrhosis, Child-Pugh class C, decompensation; against the background of chronic alcohol intoxication with polyorgan manifestations: chronic gastroduodenitis, chronic pancreatitis, cardiomyopathy, and toxic polyneuropathy. Treatment was prescribed in accordance with the stationary medical care standards. In spite of treatment, the patient's condition remained severe, and signs of multiorgan insufficiency persisted. On October 4, 2017, a significant deterioration occurred, resuscitation activities were ineffective, and a biological death was diagnosed. The body of the deceased was directed for a pathological investigation with the following clinical diagnosis: toxic liver cirrhosis, ChildPugh C class, decompensation, with possible transformation into liver carcinoma; chronic pancreatitis, cardiomyopathy against a background of chronic alcohol intoxication. Death was due to multiorgan failure and acute cardiovascular insufficiency.

On autopsy, expressed edema and significantly indurated head of the pancreas with a grayish-white color with unclear structure were noted. At the same time, the body and tail retained the large-lobular surface, with elastic structure, despite the areas of sclerosis and lipomatosis. A smooth surface of the liver was also noted, despite the clinical diagnosis of liver cirrhosis.

When examining the body cavities, $500 \mathrm{~mL}$ of yellowish-red transparent content in the right pleural cavity was found. Small whitish round-shaped foci were found on visceral pleura on both sides, with dense consistency, up to $0.1 \mathrm{~cm}$ in diameter (Fig. 1a). Foci of the same nature, sometimes merging together, were found on the inner surface of the diaphragm (Fig. 1b). In the abdominal cavity, $10,000 \mathrm{~mL}$ of ascitic fluid was found. Peritoneal layers were thickened, grayish-red in color, with multiple fibrin threads and small round-shaped foci, with a trend to merge, with dense consistency, grayish white color, and a diameter from 0.5 to 1.0 $\mathrm{cm}$. Multiple adhesions between the intestinal loops, in the pelvic cavity, between the liver and the diaphragm were found. Serous membranes of abdominal organs had a reddish-gray color, with multiple fibrinous covers in the form of threads. The greater omentum was represented by a fat tissue, on the cross-section conglomerates of soldered lymph nodes were observed with a dense consistency, grayish-white in color (Fig. 1c). Mesenteric lymph nodes formed a conglomerate accompanying each loop of the small and large intestine, up to $3.0 \mathrm{~cm}$ in

\section{Karger'=}




\section{Case Reports in Gastroenterology}

Case Rep Gastroenterol 2020;14:624-631 DOI: 10.1159/000511037

c) 2020 The Author(s). Published by S. Karger AG, Basel www.karger.com/crg

Podzolkov et al.: Anaplastic Carcinoma of the Pancreas: Clinical and Morphological Characteristics

diameter (Fig. 1d), with a dense consistency, grayish-white on a cross-section. Similar changes were found in retroperitoneal lymph nodes.

After the autopsy, an urgent histological examination of tissue of the pancreatic head was carried out, in which the diffuse dissemination of tumor cells was found, which allowed diagnosing PC. On microscopy after embedding of the material, the following changes were found: the tumor of the head of the pancreas was formed by atypical cells, with spindle-cell areas, large cells with hyperchromic nuclei, mitosis figures, single areas, represented by tubular structures located among the fibrous stroma (Fig. 2a). Tumor metastases with similar structure were observed in the mesenteric, retroperitoneal lymph nodes, on the visceral pleura and the inner surface of the diaphragm. Immunohistological analysis found cytoplasmic expression of epithelial membrane antigen (EMA) (Fig. 2b), cytokeratin 7 (SC7) (Fig. 2c), and expression of single cells of cytokeratin 20 (SC20) (Fig. 2d). These changes indicated anaplastic (undifferentiated) pleomorphic cancer of the head of the pancreas with multiple lymphogenic and implantation metastases, which was one of the concomitant diseases in a pathological diagnosis.

Lobular and frame structure of the liver tissues was impaired, the parenchyma was divided by thin layers of connective tissue into areas of different sizes. There was weak proliferation of bile ducts, as well as accumulation of bilirubin in the cytoplasm of single hepatocytes. Thus, despite the smooth surface of the liver on gross investigation, the main underlying disease according to the clinical diagnosis (mono-/multilobular liver cirrhosis) was confirmed, most likely having two causes (toxic and due to ongoing obstruction of the extrahepatic bile ducts). It should be noted that, in addition to the fibrinous covers on the serous membranes of the abdominal cavity as well as on the peritoneum, abundant infiltration of polymorphonuclear leukocytes was observed, which indicates the presence of ascites and peritonitis. Anaplastic pleomorphic pancreatic cancer and mono-/multilobular liver cirrhosis of mixed etiology are comorbidities in a pathological and anatomical diagnosis.

Thus, the discrepancy of clinical and pathological anatomical diagnoses was revealed, the cause of which is the severity of the patient's condition. Death was caused by acute cardiovascular failure associated with pronounced metabolic disorders that led to the occurrence of focal necrosis in the left ventricle wall.

\section{Discussion}

The most likely cause of APC in the patient is prolonged alcohol abuse, which led to the development of chronic pancreatitis, and later malignant neoplasm of the head of the pancreas. Considering the available laboratory and instrumental data, it was not possible to find a clinical diagnosis of pancreatic head carcinoma. The conclusion of the ultrasound investigation of the pancreas and regional lymph nodes did not give rise to oncological concern. Oncomarkers CA 19-9 and REA, an increase of which is characteristic for PC, were within normal values. Typical clinical signs of cancer of the head of the pancreas were absent: pain, jaundice, and significant weight loss, which is probably due to the rapid progression of the pathological process. On histological investigation, pathologists revealed anaplastic carcinoma of the head of the pancreas G3, which indicates the pronounced malignancy of the neoplasm. Manifestations of paraneoplastic syndrome, such as increased erythrocyte sedimentation rate syndrome and mild normochromic anemia, have been interpreted by the possible transformation of cirrhosis into liver cancer. This theory was supported by a 15-fold increase in AFP level. It

\section{Karger'=}




\section{Case Reports in Gastroenterology}

\begin{tabular}{l|l}
\hline Case Rep Gastroenterol 2020;14:624-631 \\
\hline DOI: 10.1159/000511037 & $\begin{array}{l}\text { @ 2020 The Author(s). Published by S. Karger AG, Basel } \\
\text { www.karger.com/crg }\end{array}$ \\
\hline
\end{tabular}

Podzolkov et al.: Anaplastic Carcinoma of the Pancreas: Clinical and Morphological Characteristics

was not possible to examine the pancreas in more detail; CT with contrast enhancement was not possible, as the patient was diagnosed with stage 3 chronic liver disease.

This clinical case clearly demonstrates the complexities of the PC diagnosis, fast disease progression, and extremely unfavorable prognosis. It is important for clinicians to remember that this pathology often has a subclinical course, and the oncomarker levels are not always conclusive.

\section{Acknowledgement}

The authors express their gratitude to Sechenov University for its support in publishing the article.

\section{Statement of Ethics}

The published study complies with the guidelines for human studies and includes evidence that the study was conducted in an ethical manner in accordance with the Helsinki Declaration of the World Medical Association. Written informed consent was obtained from the relatives of the patient for publication of this case report and any accompanying images.

\section{Conflict of Interest Statement}

The authors have no conflicts of interest to declare.

\section{Funding Sources}

Sechenov University.

\section{Author Contributions}

V.I. Podzolkov, A.E. Pokrovskaya, and T.S. Vargina conceptualized and designed the study. All authors participated in data acquisition and performed the analysis and interpretation of the data. A.E. Pokrovskaya, T.S. Vargina, and A.B. Ponomarev helped draft the manuscript. All authors read and approved the final manuscript.

\section{References}

1 Clinical guidelines. Pancreas cancer. Association of Oncologists of Russia. Ministry of Health of the Russian Federation. 2017

2 Duell EJ, Lucenteforte E, Olson SH, Bracci PM, Li D, Risch HA, et al. Pancreatitis and pancreatic cancer risk: a pooled analysis in the International Pancreatic Cancer Case-Control Consortium (PanC4). Ann Oncol. 2012 Nov;23(11):2964-70.

3 Huang Y, Cai X, Qiu M, Chen P, Tang H, Hu Y, et al. Prediabetes and the risk of cancer: a meta-analysis. Diabetologia. 2014 Nov;57(11):2261-9.

\section{Karger'=}




\section{Case Reports in Gastroenterology}

4 Hoshimoto S, Matsui J, Miyata R, Takigawa Y, Miyauchi J. Anaplastic carcinoma of the pancreas: case report and literature review of reported cases in Japan. World J Gastroenterol. 2016 Oct;22(38):8631-7.

5 Patyutko YI, Kudashkin NE, Kotelnikov AG, Fainshtein IA, Moroz EA, Chistyakova OV. Anaplastic pancreatic cancer with osteoclast-like giant cells: course features, treatment and prognosis. Ann Surg. 2015;(4):34-8.

6 Strobel O, Hartwig W, Bergmann F, Hinz U, Hackert T, Grenacher L, et al. Anaplastic pancreatic cancer: Presentation, surgical management, and outcome. Surgery. 2011 Feb;149(2):200-8.
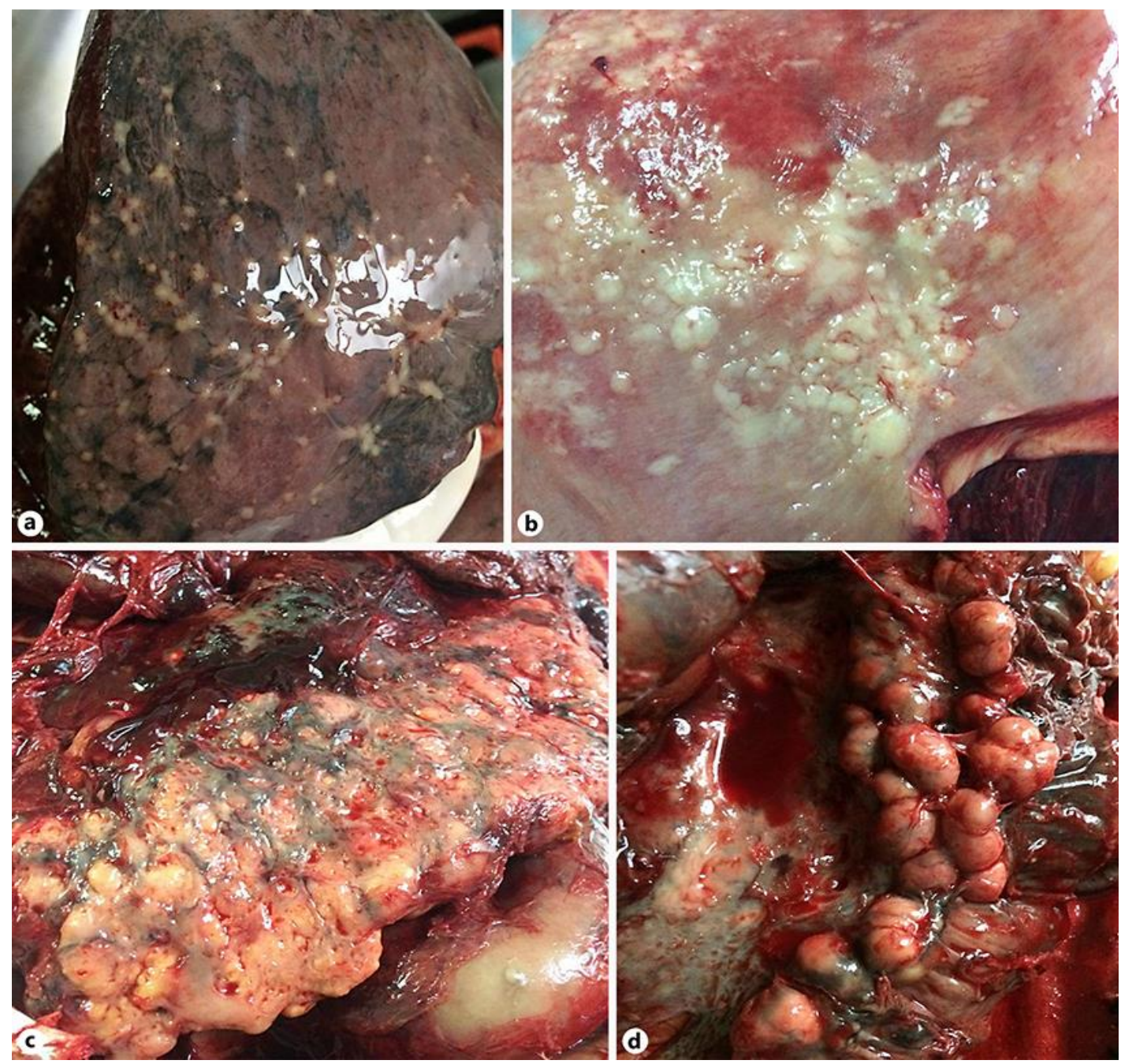

Fig. 1. a Implantation metastasis in visceral pleura. b Metastases in the inner surface of the diaphragm. c Conglomeration of lymph nodes of the large omentum. $\mathbf{d}$ Metastases into the mesenteric lymph nodes. 
Case Reports in
Gastroenterology

Case Rep Gastroenterol 2020;14:624-631

DOI: $10.1159 / 000511037$

(c) 2020 The Author(s). Published by S. Karger AG, Basel www.karger.com/crg

Podzolkov et al.: Anaplastic Carcinoma of the Pancreas: Clinical and Morphological Characteristics
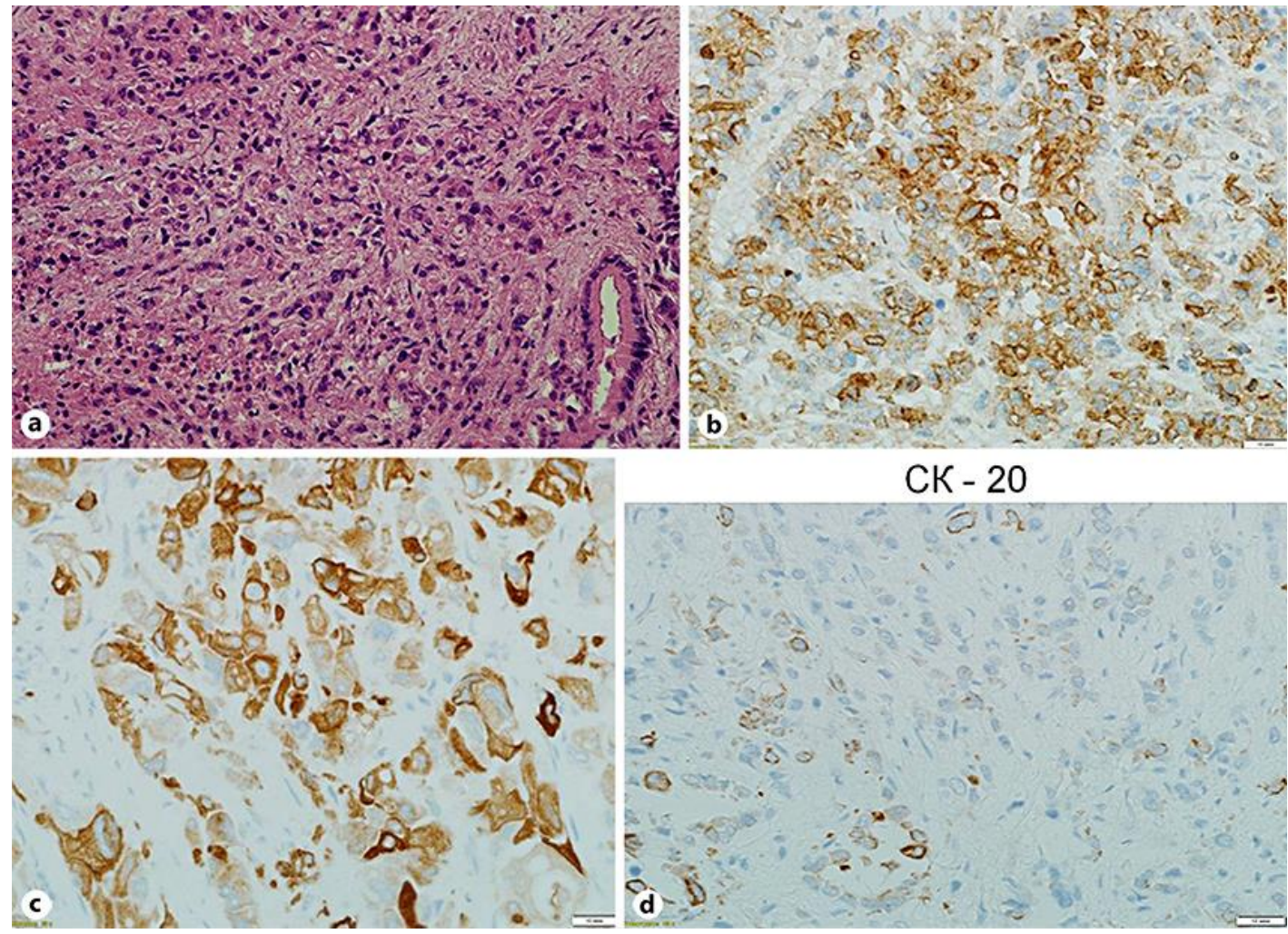

Fig. 2. a Space-occupying mass of the head of the pancreas represented by atypical cells, spindle-shaped areas, large cells with hyperchromic nuclei, mitosis figures, single sites represented by tubular structures located among fibrous stroma (hematoxylin-eosin, $\times 100$ ). b Cytoplasmic expression of epithelial membrane antigen. $\times 200$. c Cytoplasmic expression of SC7. $\times 200$. d Expression of SC20 in single tumor cells. $\times 200$. 